\title{
IAGA: a major role in understanding our magnetic planet
}

\author{
Mioara Mandea ${ }^{1}$ and Eduard Petrovsk $\dot{y}^{2}$ \\ ${ }^{1}$ Centre National d'Etudes Spatiales, 2 Place Maurice Quentin, 75001 Paris, France \\ ${ }^{2}$ Institute of Geophysics, The Czech Academy of Sciences, Boční II/1401, 14131 Prague 4, Czech Republic
}

Correspondence: Mioara Mandea (mioara.mandea@cnes.fr)

Received: 17 October 2018 - Revised: 15 December 2018 - Accepted: 4 January 2019 - Published: 16 April 2019

\begin{abstract}
Throughout the International Union of Geodesy and Geophysics's (IUGG's) centennial anniversary, the International Association of Geomagnetism and Aeronomy is holding a series of activities to underline the ground-breaking facts in the area of geomagnetism and aeronomy. Over 100 years, the history of these research fields is rich, and here we present a short tour through some of the International Association of Geomagnetism and Aeronomy's (IAGA's) major achievements. Starting with the scientific landscape before IAGA, through its foundation until the present, we review the research and achievements considering its complexity and variability, from geodynamo up to the Sun and outer space. While a number of the achievements were accomplished with direct IAGA involvement, the others represent the most important benchmarks of geomagnetism and aeronomy studies. In summary, IAGA is an important and active association with a long and rich history and prospective future.
\end{abstract}

\section{Introduction}

The International Association of Geomagnetism and Aeronomy (IAGA, Association Internationale de Géomagnétisme et d'Aéronomie - AIGA) is one of the eight associations of the International Union of Geodesy and Geophysics (IUGG). It is a non-governmental body funded through the subscriptions paid to IUGG by its Member Countries. IAGA is concerned with the understanding and knowledge that result from studies of the magnetic and electrical properties of the Earth's core, mantle and crust, the middle and upper atmosphere, the ionosphere and the magnetosphere, the Sun, the solar wind, the planets and interplanetary bodies. IAGA has a long history and can trace its origin to the Commission for Terrestrial Magnetism and Atmospheric Electricity, part of the International Meteorological Organisation (IMO), which was established in 1873. Following World War I, the International Research Council was established, and at meetings in London and Paris in 1918, the IUGG (Union Geodesique et Geophysique Internationale in French) was formed, with "Terrestrial Magnetism and Electricity (Magnétisme et Electricité Terrestres)" as section D, with leadership given to IMO. At the First IUGG General Assembly (Rome in 1922), the Section of Terrestrial Magnetism and Electricity became one of the constituent sections of the union. During the IVth
IUGG General Assembly (Stockholm in 1930), the sections became associations, one of them being the International Association of Terrestrial Magnetism and Electricity (IATME). In 1951, the upper atmosphere scientists expressed their interest in being recognized in IATME. It was Sydney Chapman who suggested using "geomagnetism" instead of "terrestrial magnetism" and who created the term "aeronomy", explained as "the science of the upper atmospheric regions where dissociation and ionization are important". In 1954, again in Rome, during the 20th IUGG General Assembly, the newly created association adopted its present name, the International Association of Geomagnetism and Aeronomy. For more details on the history of IAGA, the reader is referred to a comprehensive review by Fukushima (1995).

Since 2015, IAGA has been organized into six divisions and four inter-divisional commissions, each led by a chair and a co-chair. Each division may form working groups in given specialized topics, and elects officers to run the business of the working groups. The working groups are the elementary cells of the association and at that level the main scientific activities of IAGA are designed. Division I deals with the theory of planetary magnetic fields, paleomagnetism, and rock and environmental magnetism. Division II aims at improving the understanding of the dynamics, chemistry, en- 
ergetics and electrodynamics of the atmosphere-ionosphere system as well as the coupling processes. Division III is focused on understanding how energy input from the Sun and solar wind influence and drive Earth's magnetosphere and upper atmosphere. Division IV represents research fields related to solar wind, the heliosphere, and solar magnetism. Division $\mathrm{V}$ deals with quality standards in geomagnetic data acquisition, observatory and survey procedures, geomagnetic indices, data dissemination, and analyses of magnetic data for the purpose of understanding the various sources of the magnetic field. Finally, activities of Division VI involve the investigation of all theoretical and practical aspects of the spatial distribution of electrical properties within the Earth's and planetary interiors. Four inter-division commissions (on developing countries, history, education and outreach, and space weather) complete the internal IAGA structure. Moreover, IAGA is involved in several union and inter-association activities. The current activities of IAGA are due to efforts made during decades and even centuries by researchers involved in the Earth's magnetism, aeronomy and solar magnetic field. The breadth and complexity of research carried out within IAGA was reflected in five volumes of the IAGA Special Sopron Book Series published by Springer.

Besides the scientific activities, IAGA also plays a major role in the exchange and dissemination of scientific information between the various scientific communities in developing countries. The Interdivisional Commission on Developing Countries aims to increase the participation of developing countries in IAGA activities. Notable are the IAGA efforts for early career scientists. Since 2013, IAGA has organized the "IAGA School" (Fig. 1) during the week before the IAGA Scientific Assemblies and the IUGG General Assemblies with the aim of providing excellent early career scientists with a good basic understanding of a wide range of the scientific topics covered by IAGA. The IAGA-sponsored participants include the recipients of the IAGA Young Scientist Awards, and a number of PhD students or young postdocs, who are nominated by the IAGA Divisions and Working Groups. The Interdivisional Commission on Education and Outreach is deeply involved in these activities.

The current structure of IAGA is presented at http://www. iaga-aiga.org/ (last access: 18 January 2019). On the same website, information on how IAGA is administered by an Executive Committee on behalf of IUGG Member Countries, in accordance with the Association's Statutes and By-Laws, can be found. The website provides a wide range of information about the association's activities, from the meetings, products and services to awards and honors. The full list of IAGA resolutions is also available, as well as all IAGA Newsletters.

The IAGA Presidents and Secretaries General have been pioneers and well-known scientists in the modern world of geomagnetism and aeronomy, e.g. Aikitsu Tanakadate (Fig. 2). The full list of those who served IAGA can be found on the IAGA website. However, we have to mention here two other great names: Sydney Chapman, who acted as President

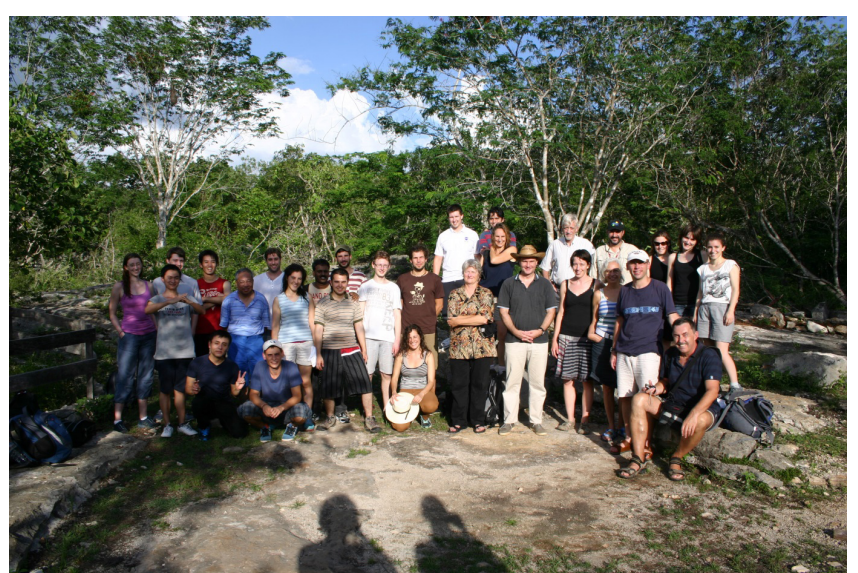

Figure 1. Participants of the first IAGA School, held in Merida, Mexico, in 2013, during the trip to inland Yucatan cenotas.

of the International Association of Meteorology and Atmospheric Sciences (IAMAS) from 1936 to 1948, President of IAGA from 1948 to 1951, President of IUGG from 1951 to 1954, and President of the Special Committee for the International Geophysical Year, and Valery Troitskaya from the Soviet Union, who was the first woman president of any IUGG association (IAGA President between 1971 and 1975).

In order to acknowledge significant scientific achievements as well as service to the community, IAGA presents several medals and awards. The most prestigious is the Shen Kuo Award, introduced in 2006 (IAGA News 43). Outstanding long-term service to the IAGA community in technical or managerial positions is acknowledged by the Long Service Award (introduced in 1988, IAGA News 27). The Young Scientist Award (introduced in 2005, IAGA News 43) is addressed to young scientists for outstanding contributions at meetings and workshops for which IAGA is a major sponsor. Finally, since 1980 (IAGA News 19), a person who has given outstanding service to IAGA may be elected an Honorary Member of IAGA.

Information on the IAGA activities has been published regularly since 1966 through the annual IAGA News (Fig. 3; all issues of the IAGA News are available on the IAGA website). The following statement can be found in the first issue of the IAGA News: "One should express a wish that all the investigators carrying on this work publish the information quickly. This would give an opportunity to coordinate the work, made by different investigators in different countries in a better way." The role of IAGA is clearly noted.

During the last century IAGA provided official (via resolutions) and organizational support to several high-profile scientific programmes, including the Second International Polar Year (IPY) in 1932-1933, the International Geophysical Year (IGY) in 1957-1958, the International Years of the Quiet Sun (IQSY) in 1964-1965, and more recently, two international efforts in 2007-2008 to commemorate the 50th anniversary 


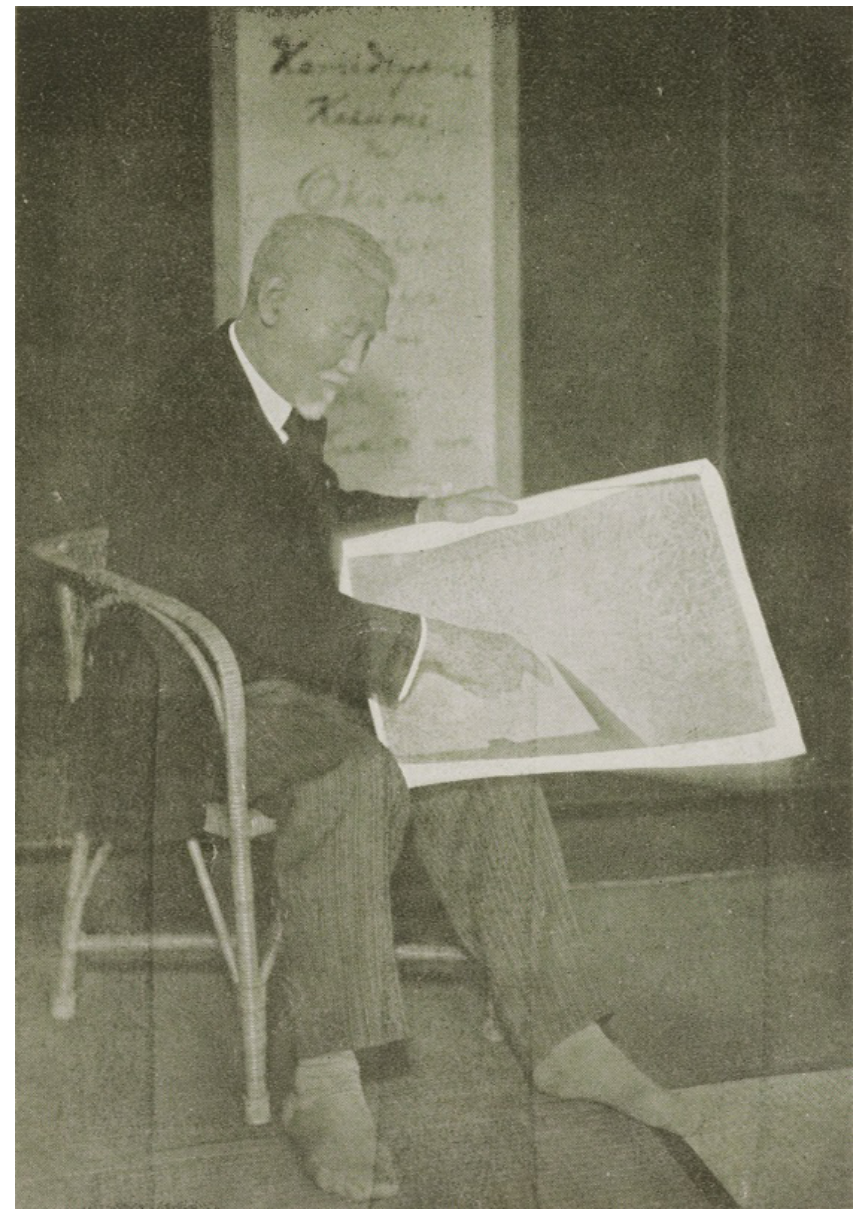

Figure 2. Aikitsu Tanakadate (1856-1952, Japan), the first President of IAGA, who measured the Earth's gravity and magnetic fields across Japan and established a latitude observatory in Mizusawa in 1899.

of the IGY: International Heliophysical Year (IHY) and Electronic Geophysical Year (eGY).

In the following, the scientific landscape of the association is reviewed from its foundation until the present. The review is complicated by the diverse studies carried out within IAGA (from geodynamo up to the Sun and outer space), as well as a huge number of facts and achievements, either accomplished with IAGA involvement, or representing the most important benchmarks of geomagnetism studies. Therefore, in this paper, only a flavor of the IAGA heritage is presented.

\section{Geomagnetic landscape before IAGA}

The history of IAGA is linked to the history of the Earth's magnetic field, the origin of it being the most challenging scientific question for many centuries. In fact, Albert Einstein once ranked the source of the Earth's magnetism among the most important unsolved problems in classical physics.
The magnetic compass was used already in the 4th century BC in China. However, the magnetic declination, denoting the difference between the magnetic and geographic north, was first recognized by Shen Kuo in 1088 (to recognize this notable person, IAGA named its highest award after him). In Europe, one of the first key names in geomagnetism remains Pierre de Maricourt, known as Petrus Peregrinus ("the pilgrim"). In his "Epistola de Magnete", written in 1269 and translated into English during the 20th century (Arnold, 1904), de Maricourt describes the pivoted compass he carefully devised and the concept of magnetic poles.

At the beginning of the 17th century a debate on local versus global departures of the field from that of an axial dipole pitted William Gilbert (with his "De Magnete", published in 1600) against Guillaume le Nautonier (with his "Mecometrie de l'eymant", published in 1601), as shown in Mandea and Mayaud (2004). Gilbert's work resolved long-lasting discussion and experiments concerning magnetism and measurements by the magnetic needle, and magnetism became the first property to be attributed to the body of the Earth as a whole. During this century, the number of measurements of magnetic directional elements increased. The Royal Society in London and the Académie des Sciences in Paris supported the building of astronomical observatories and also fostered magnetic research.

At the end of the 17th and the beginning of the 18th centuries, significant progress was made in the fields of electricity and magnetism. One of the major discoveries to be recalled, relevant to some areas of geomagnetism, was associated with the activity of Edmund Halley, the leader of the first global magnetic survey (1698-1700) on the Paramore (e.g. Thrower, 1981). The classical charts of lines of equal values of declination obtained during the survey (in 1701 for the Atlantic and in 1702 for the world) are still relevant. The first half of the next century paved the way from laboratory instruments to magnetic observatories. Von Humboldt, Gauss and Weber were deeply involved in running observatories, which formed the Göttingen Magnetic Union (Magnetischer Verein). As early as in 1836, Gauss advocated measuring the full magnetic vector and not only directional values. In the same epoch, the simultaneity of magnetic disturbances over large areas was confirmed, and Gauss developed his general theory of geomagnetism and showed that almost all of the magnetic field observed at the Earth's surface originated inside the Earth (Gauss, 1839).

The number of highlights to be traced back to the 18th and 19th centuries is large, and it is far beyond the scope of this work to name all of them. The interested reader is referred to Courtillot and le Mouel (2007), Gubbins and HerreroBervera (2007), and Cliver and Petrovsky (2019). In the following, we focus on a few of the achievements of the scientists from the IAGA community, in order to highlight the importance of the magnetic field observation and modelling, as well as processes linked to the origin of the Earth's magnetic field and solar-terrestrial relationship. 


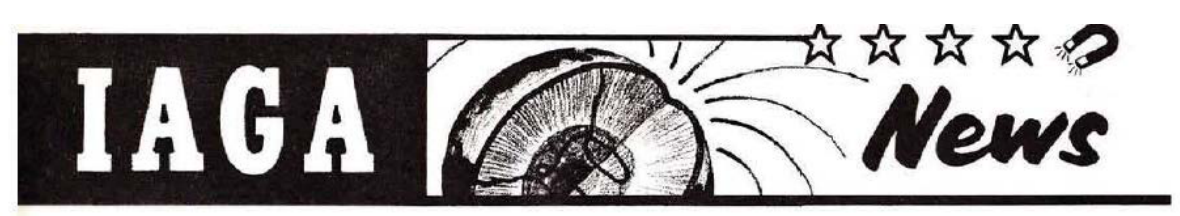

December 1963

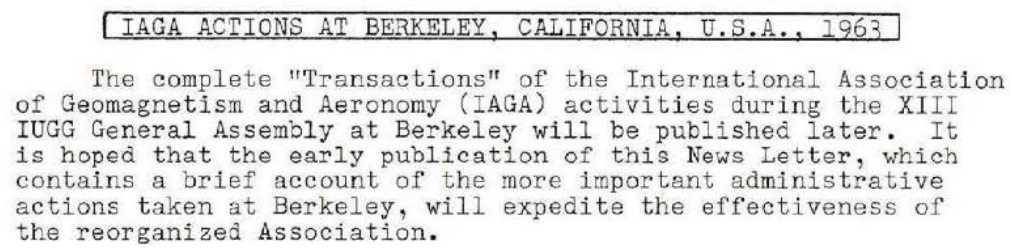

Figure 3. The first issue of the IAGA News.

\section{Earth's magnetic field - role of observations and theory}

\subsection{Magnetic observatories}

Since the time of Gauss, the number of geomagnetic observatories has grown to about 200, partly due to international efforts such as the International Polar Year in 1882-1883, the Second International Polar Year in 1932-1933 and the International Geophysical Year in 1957-1958. Important steps in establishing the global network of cooperating digital magnetic observatories, including adoption of modern standard specifications for measuring and recording equipment, have been accomplished by Division V. The role of observatories was and still is essential in monitoring the variations of the geomagnetic field, both for science and for commercial and governmental usages.

To facilitate the work at observatories, several IAGA guides for observatory practice were written over the years (Wienert, 1970; Jankowsky and Sucksdorff, 1996; and the dedicated chapters in Mandea and Korte, 2011). The nature of the observatory work has changed considerably over the years. Currently, the observatories produce their data in digital form. New techniques in instrumentation have made it possible to automate part of the observatory work and to increase the absolute accuracy of the data. This is crucial, because the new era with global magnetic surveys using satellites needs very ground-based accurate observatory data.

The effort to produce highly accurate data is complemented by their dissemination (through platforms such as Worlds Data Service (WDS) or INTERMAGNET). This started a half-century ago, with the proposal made by Sydney Chapman (Fig. 4).

\subsection{Magnetic satellites}

During the International Geophysical Year, the Soviet Union stunned the world with the launch of Sputnik, the first satellite ever; this tiny sphere with a radio transmitter was launched on 4 October 1957. The first spacecraft carrying a magnetometer was Sputnik 3, launched in May 1958. Twelve on-board instruments provided data on pressure and composition of the upper atmosphere, magnetic and electrostatic fields, concentration of charged particles, photons and heavy nuclei in cosmic rays. Following the Russian achievements, the NASA series of the POGO (Polar Orbiting Geophysical Observatory) and the OGO (Orbiting Geophysical Observatories) 2, 4, and 6 satellites carried out global measurements of the scalar field from October 1965 through June 1971. The first detailed magnetic observations of the Earth were performed by the MAGSAT (1979-1980), followed by Oersted (1999-2013 $\left.{ }^{1}\right)$, SAC-C (2000-2013), CHAMP (2000-2010), and Swarm (2013-), all carrying vector and absolute magnetometers. All IAGA divisions are involved and take advantage of the exceptional datasets provided by space magnetic missions.

Division I of IAGA plays an important role in planetary magnetism. Magnetometers were taken to the Moon during the later Apollo missions. The lunar magnetic field was also extensively observed by several spacecraft launched by different nations. Over the last decades, spacecraft have visited nearly all of the large bodies in the solar system, measuring their magnetic fields, as well as those of the Sun (by remote sensing) and the interplanetary magnetic field. Without naming all of them, let us recall that many spacecraft have visited Mars since the Soviet Union first launched Mars 1 in 1962. However, Mars did not relinquish its secrets until the Mars Global Surveyor spacecraft orbited this planet in 1997, demonstrating that it does not have a global magnetic field of internal origin, but that its crust is intensely magne-

\footnotetext{
${ }^{1}$ In 2018 Oersted is still in orbit, however without ground connection.
} 


\section{SELECTED ITEMS OF INTEREST}

\section{THE WORLD MAGNETIC ARCHIVE. Some notes on its}

purpose and progress by Sydney Chapman

Development of the WMA Proposal

Since October 1967 I have been trying to have made available in machine readable form the hourly values of the magnetic elements from the great store of reliable geomagnetic records accumulated since about 1850 --over a centry now. I gave to this project the name World Magnetic Archive (WMA), and proposed also as a secondary part of the reproduction on microfilm of the magnetograms from which the hourly records were taken.

Figure 4. Extract from the IAGA News 1969 devoted to archiving the geomagnetic observations and dissemination of the geomagnetic data.

tized. Considering another terrestrial planet, we would like to mention Mariner 10 in 1974 and 1975, the first spacecraft to visit Mercury. The MESSENGER spacecraft has mapped the Hermean magnetic field, and the two spacecraft of the BepiColombo mission will orbit Mercury in the near future. The magnetic fields of giant planets have been surveyed by the Cassini and Juno missions, among others.

The discovery of the solar wind has been an outstanding achievement in heliophysics and space physics (for this early history, the reader is referred to Obridko and Vaisberg, 2017). The first satellites designed to observe the interplanetary medium were NASA Pioneers 5, 6, 7, 8 and 9, launched between 1960 and 1968. In the 1970s, two HELIOS spacecraft provided valuable new data on the solar wind and corona. One of the most important solar missions to date has been the Solar and Heliospheric Observatory (SOHO), launched in 1995. The Solar Dynamics Observatory (SDO) spacecraft, launched in 2010, has provided a closer look at the Sun, the source of all space weather effects. The solar wind and the heliosphere are a natural plasma laboratory energized by constant free energy input from the Sun. Division IV as well as the newly formed Interdivisional Commission on Space Weather are involved in these research fields.

\subsection{Geodynamo, paleomagentism and archeomagnetism, magnetotellurics}

Larmor (1919) proposed that the magnetic field of the Earth (and Sun) could be maintained by a self-excited dynamo. This idea became generally accepted some 20 years later, assuming that magnetohydrodynamic dynamo theory in a liquid core is responsible for a self-sustaining dynamo. However, the main development was facilitated by computational and experimental facilities during the last decades of the 20th century, with the first demonstration of a successful ("Earthlike") numerical dynamo by Glatzmaier and Roberts (1995a, b).
This development, along with natural curiosity in the history of the geomagnetic field, represents the main justification for paleomagnetism and archeomagnetism, research fields which aim to get information about the intensity and direction of the geomagnetic field over the whole of geological history. Moreover, paleomagnetism helps in understanding processes in the geological history of the Earth, such as reversals of the geomagnetic field, sea-floor spreading, and plate tectonics (introduced already by Wegener in 1915). Actually, the first clear geophysical evidence of continental drift was provided by Runcorn (1956a, b) and Irving (1956), who constructed apparent polar wander paths for Europe and North America.

In the late 50 s and early 60 s of the last century, magnetic stripes were recorded by a magnetometer towed behind a vessel above the sea floor (Mason and Raff, 1961; Raff and Mason, 1961). A Canadian geophysicist, Lawrence Morley, was one of the first to suggest that the magnetic anomalies could be a kind of tape recorder of the symmetric spreading of the ocean floor through time. In early 1963, Morley submitted his hypothesis to Nature and then to the Journal of Geophysical Research. Both journals rejected his idea as too speculative. In June of that year, he presented his idea to the Royal Society of Canada (Morley, 1967; Emiliani, 2005). In September 1963, Nature published essentially the same hypothesis by British scientists Vine and Matthews (1963). It was subsequently widely accepted, and they received credit for the idea. In time, Morley's contribution was also recognized, and the concept is now known as the Vine-Matthews-Morley hypothesis. The magnetic stripe observations remained a mystery until a generally accepted explanation was published by Vine (1966), interpreting them as records of changing polarity of geomagnetic fields during ocean-floor spreading.

Mercanton (1926) postulated that reversals of magnetic inclination found in the Northern Hemisphere would be found also in the other hemisphere, thus providing evidence that magnetic poles have undergone enormous displacements. $\mathrm{He}$ 
asked IUGG/IAGA to extend its observational (paleomagnetic) base and pointed to the need for centralized sample archiving and unification of methods to study magnetic properties of rocks. At present, many such standardized methods are used in rock, paleo and archeo magnetism, e.g. determination of paleointensity or paleopole positions and characterization of magnetic anisotropy. The IAGA paleomagnetic community realized that the increasing number of laboratories, methods, instruments, and, above all, data requires systematic archiving and easy access. Currently, several regional and global databases exist and are updated, and the Division I role in these activities should be noted.

Magnetotellurics is a method based on the natural variations of the Earth's magnetic and electric fields on the surface used to infer the subsurface electrical conductivity. The penetration depth varies from a few hundreds of metres to $10 \mathrm{~km}$ or deeper. The method was developed independently in Japan in the 1940s, and in France (Cagniard, 1953) and in the USSR during the early 1950s, and is currently widely used in exploration surveys, deep crustal and mantle studies and earthquake precursor prediction research. The important role of these activities resulted in conversion of a former working group to Division VI.

\section{Aeronomy}

The term aeronomy was introduced by Chapman (1946) in a letter to Nature, suggesting that aeronomy should replace meteorology as the "meteor is now irrelevant and misleading". This proposal was apparently not received with much support. Thus, in his short note Chapman (1953) wrote that "If, despite its obvious convenience of brevity in itself and its derivatives, it does not commend itself to aeronomers, I think there is a case for modifying my proposal so that instead of the word being used to signify the study of the atmosphere in general, it should be adopted with the restricted sense of the science of the upper atmosphere, for which there is no convenient short word." In 1960, Champan noted that "Aeronomy is the science of the upper region of the atmosphere, where dissociation and ionization are important". Today it includes the science of the corresponding regions of the atmospheres and ionospheres of the Earth and other planets.

Research in aeronomy requires, in addition to groundbased observations, access to observations obtained from rockets or satellites. IAGA has largely contributed in collaborations with other associations and in coordinating some of the worldwide activities in aeronomy during the international years starting with IGY. In those early days, IAGA Commission VIII was concerned with the "Upper atmospheric structure dealing with electrodynamics, involving aeronomic processes on neutral and ionized particles". Several continuous efforts were aimed at encouraging research in new areas. For instance, in a joint resolution issued in 1963, IAGA-IAMAP recommended global studies of lunar-induced geophysical variations, including those arising from lunar atmospheric tides, which had not been studied as much as solar tides. During the IQSY (1964-1965). Four of the 10 IQSY reporters for various disciplines (drawn from different unions, associations, and committees of ICSU) were from IAGA. In addition to the reporter for geomagnetism, the other three IQSY reporters from IAGA were for aurora, airglow, and aeronomy (Beynon, 1964). The URSI/IAGA Joint Working Group on "Structure and Dynamics of the Thermosphere, Ionosphere, and Exosphere" was established in 1974. At its 6th Scientific Assembly in 1989, IAGA decided to designate the period from September 1991 to March 1993 as the International Equatorial Electrojet Year (IEEY). An IAGA/URSI joint working group on "VLF/ELF Remote Sensing of the ionosphere and magnetosphere" (VERSIM) was set up in 1975 (originally with a different name), and this group continues to be very active, holding a biennial international workshop. In recent years, IAGA has collaborated with the International Commission on Middle Atmosphere (ICMA) of IAMAS to hold a series of workshops on "Long term changes and trends in the Atmosphere", a topic of current interest in view of the anthropogenic contribution to changes in Earth's atmosphere.

IAGA scientific assemblies have provided a platform for reporting the progress achieved in recent years in the fields of mesosphere-lower thermosphere dynamics and chemistry; vertical coupling by upward-propagating waves; ionospheric electrodynamics and structuring; thermosphereionosphere coupling, dynamics, and trends; and ionospherethermosphere disturbances and modelling (Abdu et al., 2011). All these advanced studies dramatically contributed to the understanding of the variability of Earth's ionosphere, an important component of space weather, and represent the core of activities of Division II.

\section{Magnetosphere, magnetic storms, and space weather}

The Earth's magnetosphere is the region of space surrounding our planet where its own magnetic field, rather than of the solar wind, is dominant. Although the idea of the Earth's magnetosphere can be found already in the work of Gilbert (1600), the term "magnetosphere" was first proposed by Gold (1959). The magnetosphere is controlled by the interaction of the solar wind with the Earth's magnetic field, with short-term disturbances known as geomagnetic storms. These have significant technological and societal impacts on the ground as well as on orbiting objects.

The great solar storm of September 1859 (Fig. 5), generally referred to as the Carrington Event (Carrington, 1860; Hodgson, 1860; Stewart, 1861), was related to large sunspot groups during solar cycle 10. In retrospect, we know that this solar flare (the first ever reported) was associated with a major coronal mass ejection (CME) that travelled directly 
(a)

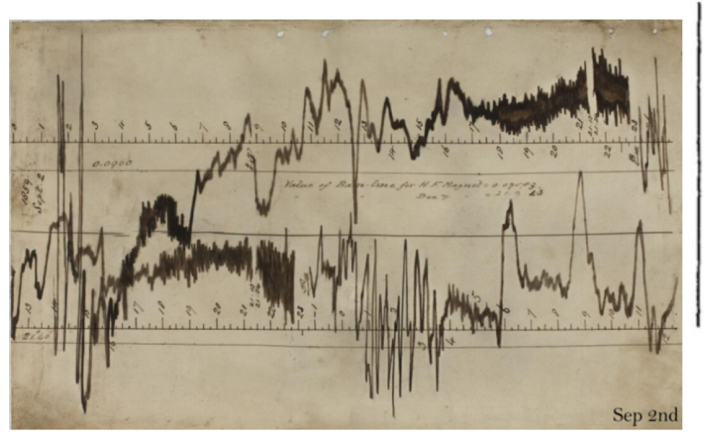

(b)

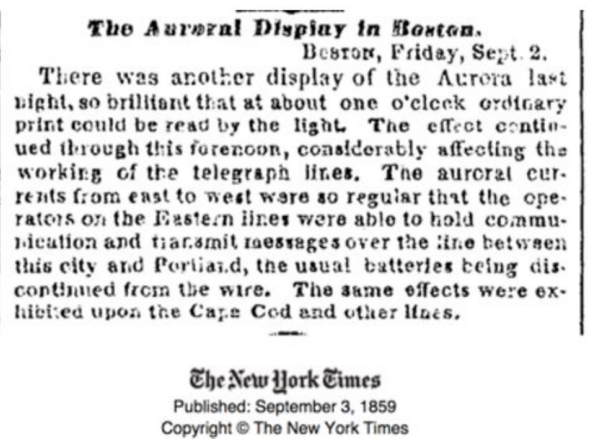

Figure 5. A magnetogram of one magnetic storm of 1859, known as the Carrington Event, the same event recorded at Greenwich Observatory in London (a); New York Times report on the same event (b).

to Earth in $17.6 \mathrm{~h}$, to cause the great storm (Bartels, 1937). Aurorae were seen around the world, those in the Northern Hemisphere as far south as the Caribbean; those over the Rocky Mountains were so bright that their glow awoke gold miners, who began preparing breakfast because they thought it was morning. People who happened to be awake in the northeastern US could read a newspaper by the aurora's light. Telegraph systems all over Europe and North America failed, in some cases giving telegraph operators electric shocks. Telegraph pylons threw sparks. Some telegraph systems continued to send and receive messages despite having been disconnected from their power supplies.

Studies have shown that a solar storm of this magnitude occurring today would likely cause widespread problems for modern civilization, mainly because of its impact on the power grid through geomagnetically induced currents or on the performance of satellite-based communication and navigation systems such as GNSS. There is an estimated $12 \%$ chance of a similar event occurring between 2012 and 2022 (Riley, 2012). For example, it is assumed that the major solar eruptive event of July 2012 was at least as strong as that in September 1859 and it was fortunate it did not occur a week earlier when the CME would have been directed to Earth (Baker et al., 2013, 2014). Divisions II, III and IV are deeply involved in space weather research. Moreover, IAGA established an Interdivisional Commission on Space Weather, which encourages research into space weather, geomagnetism and aeronomy, and on space weather impacts on society.

\section{IAGA products}

IAGA also provides several products, tools, and standards, which are developed by its Divisions and Working Groups. These efforts of all Divisions and Interdivisional Commissions are remarkable, and here we summarize a few of them.

\subsection{Models}

IGRF. The International Geomagnetic Reference Field (IGRF) is a series of mathematical models of Earth's core magnetic field and its secular variation. The models are used to calculate the large-scale, internal, part of Earth's magnetic field at times between 1900 and the present, at locations on or above the Earth's surface. IGRF has been maintained since 1968 by a working group of volunteer scientists from several international institutions, which was initiated by discussions started in the early 1960s. The IGRF models are used in e.g. studies of space weather, investigations of local magnetic anomalies, and also by commercial organizations and private individuals who often use the geomagnetic field as a source of orientation information. Temporal variations of the internal part of the geomagnetic field, which are on timescales of months to decades, require revisions of the IGRF to remain up to date and as accurate as possible. The first-generation IGRF (IGRF-1) for the period 1955-1975 was published by Zmuda (1971). At present, IGRF-12 (http://www.ngdc.noaa.gov/IAGA/vmod/igrf.html, last access: 15 October 2018) extends and updates previous versions (Finlay et al., 2010) and provides a new Definitive Geomagnetic Reference Field model for epoch 2010. Moreover, it proposes a provisional reference field model for epoch 2015 and a predictive part for epochs ranging from 2015 to 2020 (Thébault et al., 2015a, b).

WDMAM. Marine and airborne magnetic anomaly data have been collected for more than half a century, providing global coverage of the Earth. Due to the changing main field from the Earth's core, and due to differences in quality and coverage, combining these data into a consistent global magnetic grid is challenging.

The World Digital Magnetic Anomaly Map (WDMAM) project is an international effort, coordinated by IAGA and started at the end of 1970s, with the goal of integrating all available near-surface and satellite magnetic anomaly data. In 2003, a task force was created with the aim of compiling the WDMAM, combining aeromagnetic and marine data 
worldwide on a global, $5 \mathrm{~km}$ cell size, grid. The first version of the WDMAM was released in 2007 (Korhonen et al., 2007; Hemant et al., 2007) and published by the CGMW. Maus et al. (2009) and Maus (2010) continued collecting data and proposed their own map and associated magnetic field model covering spherical harmonic degrees from 16 to 720 . The main limitation of this original grid was the way the oceanic data gaps were filled. Thus, a second version of the map was produced (Lesur et al., 2016). This version was approved by IAGA during the 26th IUGG General Assembly in Prague, Czech Republic, in 2015 and publicly released (http://www.wdmam.org, last access: 15 October 2018).

\subsection{Geomagnetic indices}

In 1906, the Central Bureau of Terrestrial Magnetism for the calculation of the "International Magnetic Character" was founded and hosted by the Koninklijk Nederlands Meteorologish Instituut (De Bilt, the Netherlands) until 1987. During the IUGG meeting in Vancouver, 1987, it was decided to move the International Service of Geomagnetic Indices (ISGI) to France, and in 2015 the ISGI headquarters moved to Ecole et Observatoire des Sciences de la Terre (EOST) in Strasbourg (http://isgi.unistra.fr/index.php, last access: 15 October 2018).

A geomagnetic index is a generalized measure of the ground magnetic variations observed within a certain longitudinal range. Each index reproduces a specific electric current flowing in the near-Earth space. The evolution of geomagnetic index activity management speaks to the importance of IAGA as a reference body for policy in the matter of indices. ISGI and the ISGI collaborating institutes have the responsibility to ensure the homogeneity of the data series and the quality data stamping in close cooperation with observatories and research activities. IAGA officially recognizes several magnetic indices, aimed at describing the geomagnetic activity or some of its components: aa, am, Kp, Dst, AE, and PC. IAGA also endorses lists of remarkable geomagnetic events such as storm sudden commencement (SSC), solar flare effects (SFEs), and international quiet ( $Q$ days) and most disturbed days ( $D$-days). Criteria for IAGA endorsement of indices became effective in 2009. For more information on computation and use of geomagnetic indices, see e.g. http://isgi.unistra.fr/about_indices.php (last access: 15 October 2018) or https://www.ngdc.noaa.gov/IAGA/vdat/ (last access: 15 October 2018).

\section{IAGA in 5, 10, 100 years from now}

IAGA is and will remain a strong association in its field of activity. During the upcoming years, IAGA will play a major role in our research to understand our magnetic planet and other planetary bodies. From continuous observations to sophisticated models, the scientists of IAGA will bring new inputs in a better knowledge of how the geodynamo works, of the magnetic lithosphere, and the Earth-Sun environment and interactions. The magnetism of our solar system will continue to be observed and interpreted: the planetary magnetism will bring, undoubtedly, more surprises.

Despite all the technological progress, it is obvious that ground-based observations remain crucial for reliable recording of the geomagnetic field and its variations. Although we do have comparatively good coverage by land observatories, oceans still represent a large blank spot on the observatory map. Therefore, IAGA strongly encourages deployment of seafloor magnetic observatories, which would reduce the gap in the Earth's observation coverage and would lead to significant improvements of the geomagnetic field models and yield associated technical and societal benefits. Seafloor geomagnetic observatory programmes already exist and their installation and operation represent one of the major challenges in geomagnetism. On the other side of future IAGA activities, we can note that new satellites and planet rovers will represent major steps towards a better understanding of planetary fields and space-related events. The ESA Swarm trio of satellites, complemented by Canada's Cassiope satellite, all launched in 2013, have already brought new data needed for our understanding of how the Earth's magnetic field is generated and how it protects us from the intervention of harmful charged particles from outer space. New ideas for a constellation of NanoMagSat are under development $(\mathrm{Hu}-$ lot et al., 2018). Progress in geodynamo, paleomagnetism or magnetotellurics will be mostly determined by experimental, technological and computational facilities. These will also shape the future progress of new discipline - data assimilation, which combines the observations, models, and governing physical laws in order to identify the initial conditions and/or to obtain reliable forecasts of the system evolution. It is very likely that a number of minor steps in these fields will result in achieving more reliable and more complex knowledge of the processes in the interior and on the surface of the Earth and other planetary bodies, including their history.

Author contributions. MM and EP conceived of the presented idea. Both authors designed the paper setting and contributed to the final manuscript.

Competing interests. The authors declare that they have no conflict of interest.

Special issue statement. This article is part of the special issue "The International Union of Geodesy and Geophysics: from different spheres to a common globe" (https://www.hist-geo-space-sci. net/special_issue996.html). It is not associated with a conference. 
Acknowledgements. We would like to thank Ed Cliver and an anonymous referee for comments that greatly improved the manuscript.

Edited by: Jo Ann Joselyn

Reviewed by: Edward W. Cliver and one anonymous referee

\section{References}

Abdu, M. A., Pancheva, D., and Bhattacharyya, A. (Eds.): Aeronomy of the Earth's Atmosphere and Ionosphere, IAGA Special Sopron Series, Springer Science+Business Media B.V., Dordrecht, the Netherlands, Vol. 2, 2011.

Arnold, P.: The Letter of Petrus Pelegrinus on the Magne, A.D. 1269, McGraw and Hill, New York, 1904.

Baker, D. N., Li, X., Pulkkinen, A., Ngwira, C. M., Mays, M. L., Galvin, A. B., and Simunac, K. D. C.: A major solar eruptive event in July 2012: Defining extreme space weather scenarios, Adv. Space Res., 11, 585-591, 2013.

Baker, D. N., Jackson, J. M., and Thompson, L. K.: Predicting and mitigating socio-economic impacts of extreme space weather: benefits of improved forecasts, in: Extreme Natural Events, Disaster Risks and Societal Implications, edited by: Ismail-Zadeh, A., Fucugauchi, J., Kijko, A., Takeuchi, K., and Zaliapin, Y., Cambridge, Cambridge Univ. Press, 113-125, 2014.

Bartels, J.: Solar eruptions and their ionospheric effects - a classical observation and its new interpretation, Terr. Mag. Atmos. Elect., 42, 235-239, 1937.

Beynon, W. J. G.: The International Years of the Quiet Sun, Report prepared for UNESCO by the Committee for IQSY, 1964.

Cagniard, L.: Basic theory of the magneto?telluric method of geophysical prospecting, Geophysics, 18, 605-635, 1953.

Carrington, R. C.: Description of a Singular Appearance seen in the Sun on 1 September 1859, Mon. Not. R. Astron. Soc., 20, 13-14, 1860.

Chapman, S.: Some thoughts on nomenclature, Nature, 157, p. 405, 1946.

Chapman, S.: Nomenclature in meteorology, Weather, 7-8, 62, 1953.

Chapman, S.: The thermosphere - the Earth's outermost atmosphere, in: Physics of the Upper Atmosphere, edited by: Ratcliffe, J. A., Academic Press, New York, 1960.

Cliver, E. and Petrovsky, E.: Introduction, in: Geomagnetism, Aeronomy and Space Weather: A Journey from the Earth's Core to the Sun, edited by: Mandea, M., Korte, M., Yau, A., and Petrovsky, E., Cambridge University Press, Cambridge, UK, in print, 2019.

Courtillot, V. and Le Mouel, J. L.: The study of Earth's magnetism (1269-1950): a foundation by Peregrinus and subsequent development of geomagnetism and paleomagnetism, Rev. Geophys., 45, RG3008, https://doi.org/10.1029/2006RG000198, 2007.

Emiliani, C.: A new global Geology, in: Global Coastal Ocean, edited by: Emiliani, C., The Oceanic Lithosphere, Harvard University Press, Cambridge, MA, Vol. 7, 1687-1728, 2005.

Finlay, C. C., Maus, S., Beggan, C. D., Bondar, T. N., Chambodut, A., Chernova, T. A., Chulliat, A., Golovkov, V. P., Hamilton, B., Hamoudi, M., Holme, R., Hulot, G., Kuang, W., Langlais, B., Lesur, V., Lowes, F. J., Luehr, H., Macmillan, S., Mandea, M.,
McLean, S., Manoj, C., Menvielle, M., Michaelis, I., Olsen, N., Rauberg, J., Rother, M., Sabaka, T. J., Tangborn, A., ToffnerClausen, L., Thebault, E., Thomson, A. W. P., Wardinski, I., Wei, Z., and Zvereva, T.: International Geomagnetic Reference Field: the eleventh generation, Geophys. J. Int., 183, 1216-1230, https://doi.org/10.1111/j.1365-246X.2010.04804.x, 2010.

Fukushima, N.: History of the International Association of Geomagnetism and Aeronomy (IAGA), IUGG Chronicle, 226, 7387, 1995.

Gauss, C. F.: Allgemeine Theorie des Erdmagnetisms, Resultate aus den Beobachtungen des magnitischen Vereins im Jahre 1838, Gauss und Weber, Leipzig, Germany, 1839.

Gilbert, W.: De Magnete. Excudebat Petrus Short, London, (English translation by P. Fleury Mottelay, Dover, Mineola, New York, 1958), 240 pp., 1600.

Glatzmaier, G. H. and Roberts, P. H.: A 3-dimensional selfconsistent computer-simulation of a geomagnetic-field reversal, Nature, 377, 203-209, https://doi.org/10.1038/377203a0, 1995a.

Glatzmaier, G. H. and Roberts, P. H.: A 3-dimensional convective dynamo solution with rotating and finitely conducting inner-core and mantle, Phys. Earth Planet. Int., 91, 63-75, https://doi.org/10.1016/0031-9201(95)03049-3, 1995b.

Gold, T.: Motions in the magnetosphere of the Earth, J. Geophys. Res., 64, 1219-1224, 1959.

Gubbins, D. and Herrero-Bervera, E. (Eds.): Encyclopedia of Geomagnetism and Paleomagnetism, Springer Science+Business Media B.V., Dordrecht, the Netherlands, 2007.

Hemant, K., Thébault, E., Mandea, M., Ravat, D., and Maus, S.: Magnetic anomaly map of the world: merging satellite, airborne, marine and ground-based magnetic data sets, Earth Planet. Sc. Lett., 260, 56-71, 2007.

Hodgson, R.: On a curious appearance seen in the Sun, Mon. Not. R. Astron. Soc., 20, 15-16, 1860.

Hulot, G.: NanoMagSat: update, The Swarm 8th Data Quality Workshop, ESA-ESCRIN, Frascati, 2018.

Irving, E.: Palaeomagnetic and palaeoclimatological aspects of polar wandering, Geofis. Pura Appl., 33, 23-41, 1956.

Jankowski, J. and Sucksdorff, C.: IAGA Guide for Magnetic Measurements and Observatory Practice, International Association for Geomagnetism and Aeronomy, ISBN: 0-9650686-2-5, 1996.

Korhonen, J. V., Fairhead, J. D., Hamoudi, M., Hemant, K., Lesur, V., Mandea, M., Maus, S., Purucker, M., Ravat, D., Sazonova, T., and Thébault, E.: Magnetic Anomaly Map of the World, Geol. S. Finl., Espoo, Finland, 2007.

Larmor, J.: How could a rotating body like the Sun become a magnet?, Rep. Br. Assoc. Adv., 87, 159-160, 1919.

Lesur, V., Hamoudi, M., Choi, Y., Dyment, J., and Thébault, E.: Building the second version of the World Digital Magnetic Anomaly Map (WDMAM), Earth Planet. Space, 68, 27, https://doi.org/10.1186/s40623-016-0404-6, 2016.

Mandea, M. and Korte, M. (Eds.): Geomagnetic Observations and Models. IAGA Special Sopron Series, Springer Science+Business Media B.V., Dordrecht, the Netherlands, Vol 5, 2011.

Mandea, M. and Mayaud, P.: Guillaume Le Nautonnier - un précurseur du magnétisme terrestre, Revue d'Histoire des Sciences et de leur applications, 57, 161-174, 2004. 
Mason, R. G. and Raff, A. D.: Magnetic survey off the west coast of North America, $32^{\circ} \mathrm{N}$ latitude to $42^{\circ} \mathrm{N}$ latitude, Geol. Soc. Am. Bull., 72, 1259-1265, 1961.

Maus, S.: An ellipsoidal harmonic representation of earth's lithospheric magnetic field to degree and order 720, Geochem. Geophy. Geosy., 11, Q06015, https://doi.org/10.1029/2010GC003026, 2010.

Maus, S., Barckhausen, U., Berkenbosch, H., Bournas, N., Brozena, J., Childers, V., Dostaler, F., Fairhead, J. D., Finn, C., von Frese, R. R. B., Gaina, C., Golynsky, S., Kucks, R., Luehr, H., Milligan, P., Mogren, S., Mueller, R. D., Olesen, O., Pilkington, M., Saltus, R., Schreckenberger, B., Thebault, E., and Tontini, F. C.: EMAG2: a 2-arcmin resolution earth magnetic anomaly grid compiled from satellite, airborne, and marine magnetic measurements, Geochem. Geophy. Geosy., 10, Q08005, https://doi.org/10.1029/2009GC002471, 2009.

Mercanton, P. L.: Inversion de l'inclinaison magnétique terrestre aux ages géologiques, J. Geophys. Res., 31, 187-190, 1926.

Morley, L. W.: Letter, in: Canada's unappreciated role as a scientific innovator, edited by: Lear, J., Saturday Review, 2 September 1967, 45-50, 1967.

Obridko, V. N. and Vaisberg, O. L.: On the history of the solar wind discovery, Solar Syst. Res., 51, 165-169, https://doi.org/10.1134/S0038094617020058, 2017.

Raff, A. D. and Mason, R. G.: Magnetic survey off the west coast of North America, $40^{\circ} \mathrm{N}$ latitude to $52^{\circ} \mathrm{N}$ latitude, Geol. Soc. Am. Bull., 72, 1267-1270, 1961.

Riley, P.: On the probability of occurrence of extreme space weather events, Adv. Space Res., 10, S02012, https://doi.org/10.1029/2011SW000734, 2012.
Runcorn, S. K.: Palaeomagnetic comparisons between Europe and North America, Proc. Geol. Assoc. Canada, 8, 77-85, 1956a.

Runcorn, S. K.: Paleomagnetism, polar wandering and continental drift, Geol. Mijnbouw, 18, 253-258, 1956b.

Stewart, B.: On the great magnetic disturbance which extended from August 28 to 7 September 1859, as recorded by photography at Kew Observatory, Philos. Trans., 151, 423-430, 1861.

Thébault, E., Finlay, C. C., Beggan, C. D. et al.: International Geomagnetic Reference Field: the 12th generation, Earth Planet. Space, 67, 79, https://doi.org/10.1186/s40623-015-02289, 2015a.

Thébault, E., Finlay, C. C., and Toh, H.: International Geomagnetic Reference Field - the twelfth generation, Preface, Earth Planet. Space, 67, 158, https://doi.org/10.1186/s40623015-0313-0, 2015b.

Thrower, N. J. W. (Ed.): The Three Voyages of Edmond Halley in the Paramore, 1698-1701, Hakluyt Society, London, UK, 1981.

Vine, J. F.: Spreading of the ocean floor: new evidence, Science, 154, 1405-1415, 1966.

Vine, J. F. and Matthews, D. H.: Magnetic anomalies over oceanic ridges, Nature, 199, 947-949, 1963.

Wegener, A. F.: Die Entstehung der Kontinente und Ozeane. Druck und Verlag von Friedr. Vieweg \& Sohn, Braunschweig, Germany, 1915.

Wienert, K. A.: Notes on Geomagnetic Obserbvatory and Survey Practice, Publ. UNESCO, Brussels, Belgium, 1970.

Zmuda, A. J.: The International Geomagnetic Reference Field: Introduction, Bulletin of the International Association of Geomagnetism and Aeronomy, 28, 148-152, 1971. 